\title{
Human molecular chaperones share with SARS-CoV-2 antigenic epitopes potentially capable of eliciting autoimmunity against endothelial cells: possible role of molecular mimicry in COVID-19
}

\author{
Antonella Marino Gammazza ${ }^{1}$. Sébastien Légaré ${ }^{2,3} \cdot$ Giosuè Lo Bosco $^{4} \cdot$ Alberto Fucarino $^{1} \cdot$ Francesca Angileri $^{5}$. \\ Everly Conway de Macario ${ }^{6}$ - Alberto JL Macario ${ }^{6,7}$ • Francesco Cappello $^{1,7}$ (D)
}

Received: 10 July 2020 / Revised: 27 July 2020 / Accepted: 30 July 2020 / Published online: 4 August 2020

(C) Cell Stress Society International 2020

\begin{abstract}
Severe acute respiratory syndrome corona virus 2 (SARS-CoV-2), the cause of COVID-19 disease, has the potential to elicit autoimmunity because mimicry of human molecular chaperones by viral proteins. We compared viral proteins with human molecular chaperones, many of which are heat shock proteins, to determine if they share amino acid-sequence segments with immunogenic-antigenic potential, which can elicit cross-reactive antibodies and effector immune cells with the capacity to damage-destroy human cells by a mechanism of autoimmunity. We identified the chaperones that can putatively participate in molecular mimicry phenomena after SARS-CoV-2 infection, focusing on those for which endothelial cell plasma-cell membrane localization has already been demonstrated. We also postulate that post-translational modifications, induced by physical (shear) and chemical (metabolic) stress caused respectively by the risk factors hypertension and diabetes, might have a role in determining plasma-cell membrane localization and, in turn, autoimmune-induced endothelial damage.
\end{abstract}

Keywords Severe acute respiratory syndrome coronavirus 2 - COVID-19 · Molecular chaperones · Molecular mimicry · Autoimmunity $\cdot$ Endothelialitis

\section{Introduction}

Severe acute respiratory syndrome corona virus 2 (SARSCoV-2) causes COVID-19, a disease manifested with a wide spectrum of signs and symptoms, from a paucisymptomatic flu-like syndrome to a devastating multiorgan failure (MOF) (Wynants et al. 2020).

Electronic supplementary material The online version of this article (https://doi.org/10.1007/s12192-020-01148-3) contains supplementary material, which is available to authorized users.

Francesco Cappello

francesco.cappello@unipa.it

1 Department of Biomedicine, Neuroscience and Advanced Diagnostics (BIND), University of Palermo, Palermo, Italy

2 Département d'Informatique de l'ÉNS, ÉNS, CNRS, Université PSL, Paris, France

3 Centre de Recherche Inria de Paris, Paris, France

4 Department of Mathematics and Computer Science, University of Palermo, Palermo, Italy
Histopathological lesions of the lungs were the first to be reported, but soon after similar morphological damages (mainly diffuse microthrombosis and disseminated intravascular coagulation or DIC) were found also in other organs, including liver, kidney, and brain (Sessa et al. 2020). Virtually all organs present these histological features that may have a common mechanism: endothelialitis due to an

5 Centre Léon Bérard, Cancer Research Center of Lyon, Université de Lyon, Université Claude Bernard Lyon 1, INSERM 1052, CNRS 5286, Lyon, France

6 Department of Microbiology and Immunology, School of Medicine, University of Maryland at Baltimore-Institute of Marine and Environmental Technology (IMET), Baltimore, MD 21202, USA

Euro-Mediterranean Institute of Science and Technology (IEMEST), Palermo, Italy 
autoimmune attack against endothelial cells of vessels (Ackermann et al. 2020).

Many clinical reports (including those concerning putative efficacious therapies in COVID-19 patients) support the autoimmune theory. However, only a few have suggested that molecular mimicry may be at the basis of immunological cross-reactivity between viral and human molecules, thereby playing an active role in generating autoimmunity in COVID19 (Cappello 2020a, b; Sedaghat and Karimi 2020; Cappello et al. 2020; Angileri et al. 2020a, b; Lucchese and Flöel 2020).

We postulate that molecular chaperones (many of which are heat shock proteins) must be considered among the main suspects of molecular mimicry phenomena for various reasons: (1) they are evolutionary ancient and highly conserved (Feder and Hofmann 1999; Cappello et al. 2019). Consequently, they share epitopes not only between different species but also between them and other proteins; (2) their canonical localization is intracellular, but they may also occur in the plasma-cell membrane and extracellularly, which allows their encountering the immune system provoking an immune reaction, especially if they have undergone posttranslational modifications (PTM) (Balogi et al. 2019; Caruso Bavisotto et al. 2020); and (3) autoimmunity generated by antigenic epitopes cross-reactive between human molecular chaperones and microbial molecules have already been described in various diseases, and the autoimmune reaction involves also endothelial cells (Lamb et al. 2003; Cappello et al. 2009).

The above findings and considerations encouraged us to search for SARS-CoV-2 protein molecular mimicry of human molecular chaperones that could generate immunological cross-reactivity in COVID-19.

We compared the amino acid sequences of all the SARS$\mathrm{CoV}-2$ proteins with the sequences of human chaperones to determine if they share segments with immunogenic-antigenic potential that might be causing autoimmunity. Particularly, we focused on molecular chaperones that have already been shown to be present in endothelial cells.

\section{Materials and methods}

We performed an exhaustive search of all contiguous segments of SARS-CoV-2 proteins with an exact identity to human protein segments. We implemented a sliding window approach to systematically compare all segments of viral and human proteins (Polimeno et al. 2008; Lucchese 2019). Human and SARS-Cov-2 protein sequence files were downloaded from UniProt database. Only segments with a length of six amino acids or more were considered.

Further analyses were performed using the Immune Epitope Database and analysis resource (IEDB, https://www. iedb.org/), a database of experimentally validated epitopes and a tool to predict $\mathrm{T}$ cell and B cell epitopes. We used the BebiPred 2.0 (Jespersen et al. 2017) and the Kolaskar and Tongaonkar Antigenicity scale (Kolaskar and Tongaonkar 1990), both algorithms embedded in the B cell prediction analysis tool available in IEDB (Zhang et al. 2008). For CD4 T and CD8 T cell epitope prediction, we applied previously described algorithms developed to predict dominant HLA class I and dominant HLA class II epitopes (Paul et al. 2013, 2015).

\section{Results}

Sequence analysis of 20,365 human proteins showed that 3781 share peptides of at least six amino acids ( $\geq 6$ mer) with SARS-CoV-2 proteins, and 17 of them are molecular chaperones. Notably, all the shared peptides between chaperones and viral proteins are part of immunogenic epitopes predicted using IEDB for either B or T lymphocytes (Table 1).

\section{Discussion}

COVID-19 is a disease that, in some subjects, can be lethal (Lippi et al. 2020). The main risk factors associated with a poor prognosis are hypertension and diabetes, which can generate, respectively, physical (shear) or chemical (metabolic) stress to endothelial cells. And we know that stress can induce molecular chaperones to migrate to the plasma-cell membrane and to exit the cell, probably after being modified (Caruso Bavisotto et al. 2020) and, consequently, can be met by the immune system and recognized as foreign antigens. This would elicit an autoimmune response. The substantial number of DNAJ family proteins that we found (Table 1) could be a clue of this hypothesis, because of its cellular location (i.e., on plasma membrane) and its pathways to exposure to the immune response (Kotlarz et al. 2013).

The results obtained by the bioinformatics prediction tool for immunogenic epitopes showed that the shared peptides between 17 human chaperones and viral proteins have a high likelihood of being recognized by the human immune system, triggering an autoimmune reaction. As reported in the supplemental material (Table S1), these chaperones are widely expressed in human tissues and some of them are on the plasma-cell membrane under normal conditions. We hypothesize that cell stress (shear and/or metabolic) associated with COVID-19 triggers the translocation of chaperone molecules from their intracellular location to the plasma-cell membrane and extracellular space and, thus, creates the conditions for autoimmunity. In this brief report, we decided to focus on endothelial cells because COVID-19 characteristics point to an autoimmune attack against these cells, which substantiates our hypothesis. 


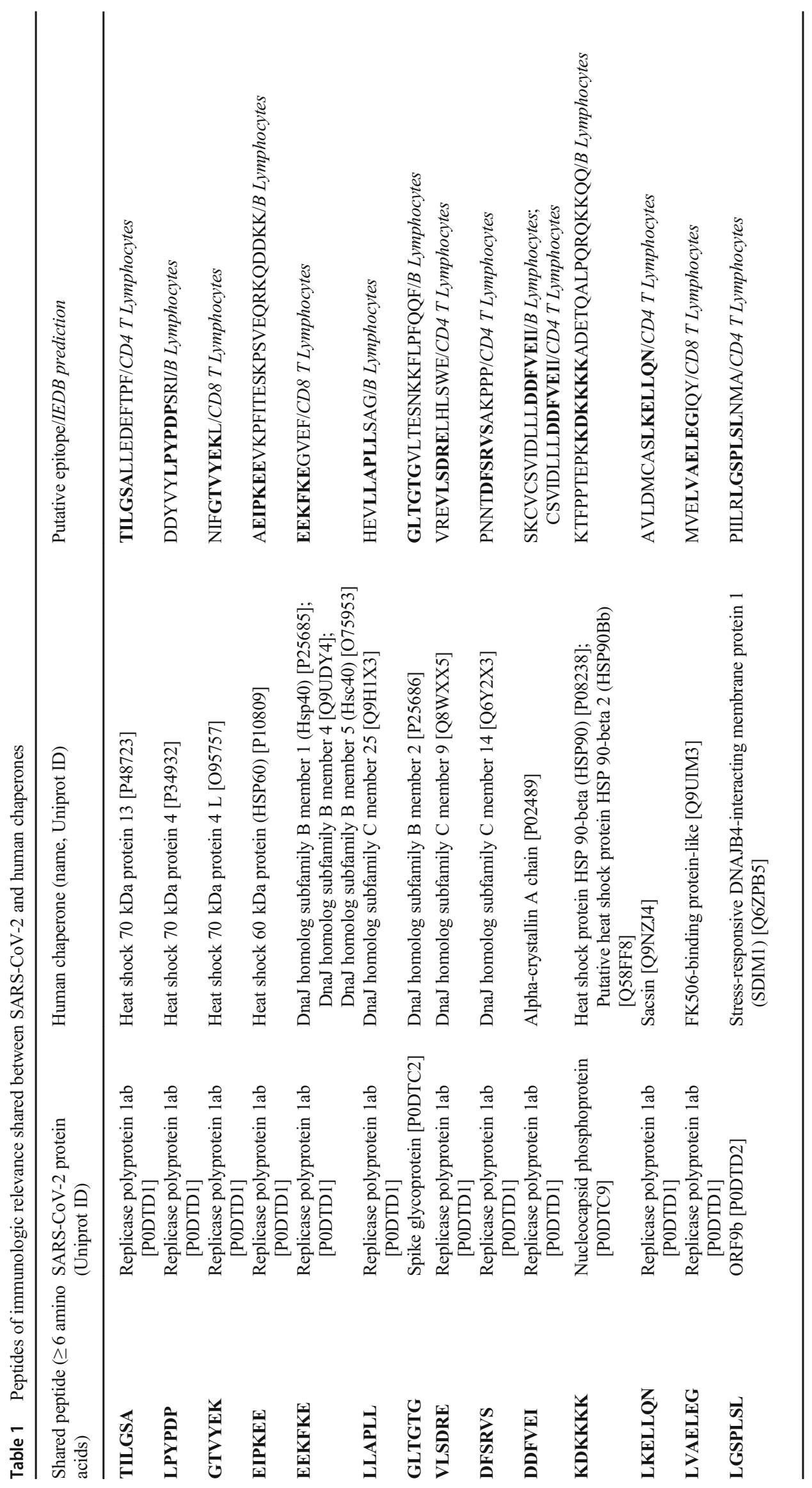


Literature data support this hypothesis. It has been demonstrated that stress agents induce HSP90 localization on the surface of primary human endothelial cells (Profumo et al. 2018), and HSP60 is present on the surface of arterial endothelial cells, initiating atherosclerosis by the recognition of atherogenic HSP60 epitopes (Almanzar et al. 2012). Moreover, the cell surface presence of HSP70 is modulated be shear stress in cultured endothelial cells and aorta endothelium, potentially restricting thromboresistance and supporting thrombosis/inflammation in stress situations (Thaís et al. 2019).

Reports about efficacy of some therapies in COVID-19 patients also tend to support the autoimmune hypothesis (Saghazadeh and Rezaei 2020; Prete et al. 2020; Picchianti Diamanti et al. 2020). Advances in the elucidation of the role of autoimmunity, as hypothesized here, will be made as more autopsies are carried out on COVID-19 victims. We have remarked on the need of information that can only be obtained by autopsy, which in some countries such as Italy is scarce (Pomara et al. 2020). This fact delayed the realization that COVID-19 was not just a severe pneumonia but a systemic disease, and resulted in a lack of material to study, e.g., by immunohistochemistry and immunomorphological techniques, the histopathological manifestation of the disease.

Availability of tissues from victims of COVID-19 will allow dissection of the cellular and molecular patterns and mechanisms underpinning the damage of epithelia and other structures that ultimately cause death. It will, thus, be possible to assess the validity of our hypothesis, which emphasizes the role of autoimmunity due to molecular mimicry in the pathogenicity of COVID-19. Finally, studies on molecular mimicry phenomena will also help in directing experiments and clinical trials for producing safe and efficacious vaccines, as already indicated by others (Lucchese 2020).

Funding information AMG, FC, and GLB were partially supported by the University of Palermo. SL was partially supported by the Université PSL and Centre de Recherche Inria de Paris. FA was partially supported by the Universite de Lyon. AJLM and ECdeM were partially supported by IMET. FC and AJLM were partially supported also by IEMEST. This is IMET contribution number IMET 20-015.

\section{References}

Ackermann M, Verleden SE, Kuehnel M, Haverich A, Welte T, Laenger F, Vanstapel A, Werlein C, Stark H, Tzankov A, Li WW, Li VW, Mentzer SJ, Jonigk D (2020) Pulmonary vascular endothelialitis, thrombosis, and angiogenesis in COVID-19. N Engl J Med 383(2):120-128. https://doi.org/10.1056/NEJMoa2015432

Almanzar G, Öllinger R, Leuenberger J, Onestingel E, Rantner B, Zehm S, Cardini B, van der Zee R, Grundtman C, Wick G (2012) Autoreactive HSP60 epitope- specific T-cells in early human atherosclerotic lesions. J Autoimmun 39(4):441-450. https://doi.org/ 10.1016/j.jaut.2012.07.006
Angileri F, Légaré S, Marino Gammazza A, Conway de Macario E, Macario AJL, Cappello F (2020a, 2020) Is molecular mimicry the culprit in the autoimmune haemolytic anaemia affecting patients with COVID-19? [published online ahead of print, 2020 May 26]. Br J Haematol. https://doi.org/10.1111/bjh.16883

Angileri F, Légaré S, Marino Gammazza A, Conway de Macario E, Macario AJL, Cappello F (2020b, 2020) Molecular mimicry may explain multi-organ damage in COVID-19 [published online ahead of print, 2020 Jun 11]. Autoimmun Rev:102591. https://doi.org/10. 1016/j.autrev.2020.102591

Balogi Z, Multhoff G, Jensen TK, Lloyd-Evans E, Yamashima T, Jäättelä M, Harwood JL, Vígh L (2019) Hsp70 interactions with membrane lipids regulate cellular functions in health and disease. Prog Lipid Res 74:18-30. https://doi.org/10.1016/j.plipres.2019.01.004

Cappello F (2020a) Is COVID-19 a proteiform disease inducing also molecular mimicry phenomena? Cell Stress Chaperones 25(3): 381-382. https://doi.org/10.1007/s12192-020-01112-1

Cappello F (2020b) COVID-19 and molecular mimicry: the Columbus' egg? J Clin Neurosci 77:246. https://doi.org/10.1016/j.jocn.2020. 05.015

Cappello F, Conway de Macario E, Di Felice V, Zummo G, Macario AJL (2009) Chlamydia trachomatis infection and anti-Hsp60 immunity: the two sides of the coin. PLoS Pathog 5(8):e1000552. https://doi. org/10.1371/journal.ppat.1000552

Cappello F, Conway de Macario E, Macario AJL (2019) HSP60: a story as long as life on the earth. In: Asea A, Kaur P (eds) Heat shock protein 60 in human diseases and disorders. Heat Shock Proteins, vol 18. Springer Nature Publishers, Dordrecht), 2020. https://doi. org/10.1007/7515_2020_1

Cappello F, Marino Gammazza A, Dieli F, Conway de Macario E, Macario AJL (2020) Does SARS-CoV-2 trigger stress-induced autoimmunity by molecular mimicry? A hypothesis. J Clin Med 9(7): E2038. Published 2020 Jun 29. https://doi.org/10.3390/jcm9072038

Caruso Bavisotto C, Alberti G, Vitale AM, Paladino L, Campanella C, Rappa F, Gorska M, Conway de Macario E, Cappello F, Macario AJL, Marino Gammazza A (2020) Hsp60 post-translational modifications: functional and pathological consequences. Front Mol Biosci 7:95. https://doi.org/10.3389/fmolb.2020.00095

Feder ME, Hofmann GE (1999) Heat-shock proteins, molecular chaperones, and the stress response: evolutionary and ecological physiology. Annu Rev Physiol 61:243-282. https://doi.org/10.1146/ annurev.physiol.61.1.243

Jespersen MC, Peters B, Nielsen M, Marcatili P (2017) BepiPred-2.0: improving sequence-based B-cell epitope prediction using conformational epitopes. Nucleic Acids Res 45(W1):W24-W29

Kolaskar AS, Tongaonkar PC (1990) A semi-empirical method for prediction of antigenic determinants on protein antigens. FEBS Lett 276(1-2):172-174. https://doi.org/10.1016/0014-5793(90)80535-q

Kotlarz A, Tukaj S, Krzewski K, Brycka E, Lipinska B (2013) Human Hsp40 proteins, DNAJA1 and DNAJA2, as potential targets of the immune response triggered by bacterial DnaJ in rheumatoid arthritis. Cell Stress Chaperones 18:653-659. https://doi.org/10.1007/ s12192-013-0407-1

Lamb DJ, El-Sankary W, Ferns GA (2003) Molecular mimicry in atherosclerosis: a role for heat shock proteins in immunisation. Atherosclerosis 167(2):177-185. https://doi.org/10.1016/s00219150(02)00301-5

Lippi G, Sanchis-Gomar F, Henry BM (2020) COVID-19: unravelling the clinical progression of nature's virtually perfect biological weapon. Ann Transl Med 8(11):693. https://doi.org/10.21037/ atm-20-3989

Lucchese G (2019) Herpesviruses, autoimmunity and epilepsy: peptide sharing and potential cross-reactivity with human synaptic proteins. Autoimmun Rev 18:102367. https://doi.org/10.1016/j. autrev.2019.102367 
Lucchese G (2020) Epitopes for a 2019-nCoV vaccine. Cell Mol Immunol 17:539-540. https://doi.org/10.1038/s41423-020-0377-z

Lucchese G, Flöel A (2020) Molecular mimicry between SARS-CoV-2 and respiratory pacemaker neurons. Autoimmun Rev 19(7):102556. https://doi.org/10.1016/j.autrev.2020.102556

Paul S, Weiskopf D, Angelo MA, Sidney J, Peters B, Sette A (2013) HLA class I alleles are associated with peptide-binding repertoires of different size, affinity, and immunogenicity. J Immunol 191: 5831-5839

Paul S, LindestamArlehamn CS, Scriba TJ, Dillon MB, Oseroff C, Hinz D, McKinney DM, Carrasco Pro S, Sidney J, Peters B, Sette A (2015) Development and validation of a broad scheme for prediction of HLA class II restricted T cell epitopes. J Immunol Methods 422: 28-34

Picchianti Diamanti A, Rosado MM, Pioli C, Sesti G, Laganà B (2020) Cytokine release syndrome in COVID-19 patients, a new scenario for an old concern: the fragile balance between infections and autoimmunity. Int J Mol Sci 21(9):3330. https://doi.org/10.3390/ ijms 21093330

Polimeno L, Mittelman A, Gennero L, Ponzetto A, Lucchese G, Stufano A, Kusalik A, Kanduc D (2008) Sub-epitopic dissection of HCV E1 315-328 HRMAWDMMMNWSPT sequence by similarity analysis. Amino Acids 34(3):479-484

Pomara C, Li Volti G, Cappello F (2020) COVID-19 deaths: are we sure it is pneumonia? Please, autopsy, autopsy, autopsy! J Clin Med 9(5): 1259. https://doi.org/10.3390/jcm9051259

Prete M, Favoino E, Catacchio G, Racanelli V, Perosa F (2020) SARS$\mathrm{CoV}-2$ inflammatory syndrome. Clinical features and rationale for immunological treatment. Int J Mol Sci 21(9):3377. https://doi.org/ 10.3390/ijms21093377

Profumo E, Buttari B, Tinaburri L, D’Arcangelo D, Sorice M, Capozzi A, Garofalo T, Facchiano A, Businaro R, Kumar P, Singh BK, Parmar VS, Saso L, Riganò R (2018) Oxidative stress induces HSP90 upregulation on the surface of primary human endothelial cells: role of the antioxidant 7,8-dihydroxy-4-methylcoumarin in preventing HSP90 exposure to the immune system. Oxidative Med Cell Longev:2373167. https://doi.org/10.1155/2018/2373167

Saghazadeh A, Rezaei N (2020) Towards treatment planning of COVID19: rationale and hypothesis for the use of multiple immunosuppressive agents: anti-antibodies, immunoglobulins, and corticosteroids. Int Immunopharmacol 84:106560. https://doi.org/10.1016/j.intimp. 2020.106560

Sedaghat Z, Karimi N (2020) Guillain Barre syndrome associated with COVID-19 infection: A case report. J Clin Neurosci 76:233-235. https://doi.org/10.1016/j.jocn.2020.04.062

Sessa F, Bertozzi G, Cipolloni L, Baldari B, Cantatore S, D’Errico S, di Mizio G, Asmundo A, Castorina S, Salerno M, Pomara C (2020) Clinical-forensic autopsy findings to defeat COVID-19 disease: a literature review. J Clin Med 9(7):E2026. https://doi.org/10.3390/ jem9072026

Thaís LSA, Venturini G, Moretti AIS, Tanaka LY, Pereira AC, Laurindo FRM (2019) Cell-surface HSP70 associates with thrombomodulin in endothelial cells. Cell Stress Chaperones 24(1):273-282. https:// doi.org/10.1007/s12192-018-00964-y

Wynants L, Van Calster B, Bonten MMJ, Collins GS, Debray TP, De Vos M, Haller MC, Heinze G, Moons KGM, Riley RD et al (2020) Prediction models for diagnosis and prognosis of covid19: systematic review and critical appraisal. BMJ 369:m1328. https://doi.org/ 10.1136/bmj.m1328

Zhang Q, Wang P, Kim Y, Haste-Andersen P, Beaver J, Bourne PE, Bui HH, Buus S, Frankild S, Greenbaum J, Lund O, Lundegaard C, Nielsen M, Ponomarenko J, Sette A, Zhu Z, Peters B (2008) Immune epitope database analysis resource (IEDB-AR). Nucleic Acids Res 36:W513-W518

Publisher's note Springer Nature remains neutral with regard to jurisdictional claims in published maps and institutional affiliations. 